\title{
Study on the Reference of Russian Ice-snow Sports Resources for the Cultivation of Ice-snow Sports Talents of Colleges and Universities*
}

\author{
Changzhu Li \\ School of Physical Education \\ Heihe College \\ Heihe, China 164300
}

\begin{abstract}
This paper starts with the Russian ice-snow sports resources to analyzes the current situation of the cultivation of ice-snow sports talents in colleges and universities, explores the constraints of the cultivation of icesnow sports talents in colleges and universities, and puts forward the reference strategy of Russian ice and snow sports resources in the cultivation of ice-snow sports talents in colleges and universities.
\end{abstract}

Keywords-Russia; ice-snow sports resources; colleges and universities; ice-snow sports talents; cultivation; reference

\section{INTRODUCTION}

Russia is rich in ice and snow resources that are used in local ice and snow sports teaching, which plays an important role in the cultivation of Russian ice-snow talents. Russia actively uses local ice-snow sports resources to accelerate the cultivation of ice-snow sports talents. In the process of cultivating ice-snow sports talents, colleges and universities in China should actively refer to Russian ice-snow sports resources and strengthen the use of China's ice-snow sports resources. However, many colleges and universities have various problems in the process of training ice and snow sports talents, such as financial problems, teaching thought problems, curriculum model problems, and teacher level problems, which seriously hinders the cultivation of icesnow sports talents. Studying the role of Russian ice-snow sports resources in the training of ice-snow sports talents in colleges and universities can not only effectively promote the development of ice-snow sports teaching in colleges and universities in China, but also have a profound significance for the cultivation of Chinese ice-snow sports talents.

*This article is the key topic of humanities and social science research in Heihe College in 2017: the reference and utilization of Russian ice-snow sports resources in the development of Heilongjiang ice-snow sports industry, Question No.: RWZ201702.

This article is the key project of the "Thirteenth Five-Year Plan" of Heilongjiang Province: innovative research on Sino-Russian joint cultivation of ice-snow sports talents in colleges and universities under the perspective of "supply-side reform", subject number: GBB1318083

\section{OVERVIEW OF RUSSIAN ICE-SNOW SPORTS RESOURCES}

Russia belongs to the sub-frigid climate, and is close to the Arctic Ocean, so it is cold all year round with more snow and ice. Therefore, Russians have special feelings for ice and snow, and use ice-snow sports resources to create a unique ice-snow culture. Russians believe that ice and snow are the fun of winter and the treasure that nature has given. Moreover, Russians used abundant ice and snow resources to carry out physical education, accelerated the cultivation of ice and snow sports talents, and achieved great achievements There are also abundant ice-snow resources in northern area of China. In the process of ice-snow talent training, we can learn from the application of Russian ice-snow sports resources in the training of ice-snow sports talents.

\section{The StATUs QuO OF ICE-SNOW SPORTS PERSONNEL TRAINING}

\section{A. The Status Quo of Ice-snow Course in Colleges and Universities}

Ice-snow sports teaching has high requirement on climate and must be carried out in an outdoor environment below minus 4 degree centigrade. Therefore, the ice-snow sports courses in northern universities in China are usually opened in winter. The ice-snow sports courses in colleges and universities mainly include figure skating, speed skating, alpine skiing, ice hockey, and curling and so on. Moreover, among these courses, the number of schools offering skating courses is the highest, and there are fewer schools offering ice hockey courses. Many schools don't offer courses such as snowboarding and figure skating. This is because opening snowboarding and figure skating courses requires ample skiing field, but the cost of the skiing field is high, which is dangerous and difficult to open.

\section{B. The Current Situation of Venues and Equipment of College Ice-snow Sports Teaching}

Teaching venues and equipment are the basis and material guarantee for ice-snow teaching in colleges and universities. Although with the development of social 
economy, college sports teaching infrastructure construction has made great achievements, the construction of ice-snow sports teaching venues and equipment in many colleges and universities is still hard to meet the requirements of ice-snow teaching. Specifically, many colleges and universities do not have their own ice-snow venues, with only a small outdoor ice rink, which has seriously restricted the cultivation of icesnow talents. Moreover, the construction and maintenance of the ice rink requires a lot of manpower and material resources. There are phenomena of poor quality and delayed maintenance during the ice rink maintenance process in many schools, so the ice rink has a short service life.

\section{Current Status of Ice-snow Sports Teaching Methods in Colleges and Universities}

The ice-snow sport teaching is more practical, which requires scientific teaching methods to strengthen the guidance of students' ice-snow sports. However, at this stage, many colleges and universities are still using traditional teaching methods. Teachers teach students basic knowledge and skills about snow sports, and demonstrate ice-snow movements for students to learn ice and snow knowledge and strengthen ice-snow sport exercise. Under this teaching mode, teachers use the teaching methods such as demonstration teaching, expository method, feedback teaching method and demonstration method as the main means. However, since snow sports need to be carried out outdoor, traditional teaching methods are difficult to stimulate students' interest in ice and snow sports, and even lead to students' tiredness in ice-snow sports, which seriously affects students' ice-snow skills.

\section{The Status Quo of the Development Form of College Ice- snow Sports}

The ice-snow sport teaching in many colleges and universities in China has been carried out in the form of elective courses and compulsory courses. In this case, students can choose their own ice-snow course items according to their hobbies, snow sports level and physical fitness. At the same time, this kind of development method can redistribute students from different majors and different departments, strengthen communication among students, optimize the allocation of physical education teachers, and promote the popularization of ice-snow sports. Moreover, the ice-snow sports teaching is subject to greater temperature restrictions, so the ice-snow sports courses in colleges and universities can only be carried out in winter. Therefore, many colleges and universities do not have special ice-snow sports courses, and the ice-snow courses are only part of the physical education curriculum.

\section{E. The Status Quo of Teachers of College Ice-snow Physical Education}

College ice and snow sports teachers are the key factors in the training of ice-snow sports talents. The ice-snow sports teachers in many colleges and universities are mostly between 30 and 50 years old. The number of ice-snow sports teachers under 30 years old and the number of ice-snow sports teachers over 50 years old are fewer. Moreover, the young and middle-aged ice-snow sports teachers have good academic qualifications and rich work experience, which can effectively promote the development of ice-snow sports teaching. In terms of teacher titles, the professional titles of ice-snow teachers in many colleges and universities are low, and only a few physical education teachers have obtained professor qualifications. However, the training of ice-snow sports talents not only requires higher teaching ability and advanced teaching concepts of physical education teachers, but also needs scientific research consciousness and innovation consciousness to accelerate the innovation of icesnow sports teaching.

\section{THE CONSTRAINTS OF THE TRAINING OF ICE-SNOW SPORTS TALENTS IN COLLEGES AND UNIVERSITIES}

\section{A. Funding Factor}

Funding is an important factor restricting the training of ice-snow sports talents in colleges and universities in China. Many colleges and universities have no ability to build snow pack in the process of cultivating ice-snow sports talents, so they can only rent ice-snow venues and ice and snow equipment outside the school. Also, training in off-campus ski resorts requires a certain amount of money for transportation. Many colleges and universities have difficulty in paying for the transportation costs of ice-snow talent training. In addition, curling, figure skating and ice hockey teaching have higher requirements on the venue, which needs the school to spend a lot of money to maintain the teaching venue and rent ice-snow equipment. However, most colleges and universities have limited funding for ice-snow sports teaching, and it is difficult to pay for high venue funding, transportation expenses, and academic aid funds, which seriously restricts the training of ice-snow sports talents.

\section{B. Traditional Teaching Ideas}

Traditional teaching thoughts have seriously affected the development of ice-snow sports teaching in colleges and universities. Specifically, many colleges and universities have many problems in teaching methods, teaching evaluation and teaching methods. The ice-snow sports curriculum is relatively simple, so students lack the right to choose courses. Many students who have already had icesnow basis are prone to feel tired of ice-snow courses. At the same time, some ice-snow sports teachers pay too much attention to the use of traditional teaching methods in teaching, while neglecting other teaching methods. The teaching methods are too old, and students and teachers lack interaction in ice-snow sports. It is difficult to mobilize students to participate in the ice-snow sports initiative and enthusiasm. In addition, there are many colleges and universities in the ice-snow sports teaching concept is relatively old, lack of awareness of teaching innovation, ice and snow sports teaching content is too monotonous, it is difficult to form a characteristic ice-snow physical education curriculum. 


\section{Course Mode}

Many colleges and universities have a single mode of development, and only carry out ice-snow sports teaching in the form of elective courses and compulsory classes. Moreover, there are fewer projects in the compulsory classes, which is not conducive to the selection of students' ice-snow sports courses. At the same time, ice-snow sports courses in many colleges and universities are only carried out in the form of physical education classes. There is a lack of snow sports activities in the form of winter camps and clubs. It is difficult to stimulate students' enthusiasm in ice and snow sports.

\section{Teachers' Level}

The teachers' level has an important influence on the teaching of ice and snow sports in colleges and universities. At present, the reviews of the ice-snow sports teachers in many colleges and universities are not high. Professional icesnow sports teachers are lacking, they do not understand the development status and the future development trend of icesnow sports, and they don't have perfect knowledge and skills,so the quality of ice-snow sports teaching is not high. Moreover, there are still many teachers in colleges and universities of ice and snow sports sticking to the traditional way of education, lacking in awareness of teaching innovation, and failing in learning advanced teaching concepts and teaching methods of ice-snow sports in time. Their business quality still needs to be improved. In addition, there are ice-snow sports teachers in some colleges and universities lacking scientific research consciousness. They have not actively participated in scientific research work, which seriously restricts the discipline development and teaching development of ice-snow sports.

\section{THE REFERENCE STRATEGY OF RUSSIAN ICE-SNOW SPORTS RESOURCES IN THE CULTIVATION OF ICE-SNOW SPORTS TALENTS IN COLLEGES AND UNIVERSITIES}

\section{A. Expanding the Ice-snow Sports Project}

The ice-snow sports teaching in colleges and universities should actively learn from the application of Russian icesnow sports resources in physical education and expand the ice-snow sports project. Therefore, colleges and universities should break through the traditional ice-snow culture and ice-snow sports projects, and carry out a variety of ice-snow sports projects, so that students can deepen their feelings on ice-snow resources and ice-snow sports in the ice-snow sports projects. Moreover, colleges and universities should emphasize the fitness and entertainment of the ice-snow sports, give full play to the entertainment and fitness role of the ice-snow sports, and stimulate students' emotions towards ice-snow sports. In addition, colleges and universities should combine the characteristics of their icesnow sports teaching, strengthen the construction of icesnow sports projects, actively reform and make innovation in traditional ice-snow sports projects, and vigorously develop cooperative ice-snow sports such as ice cubes and sleds. At the same time, colleges and universities should actively encourage students to make innovation in ice-snow sports programs and increase their participation in ice-snow sports.

\section{B. Creating an Ice-snow Sports Atmosphere}

There is heating in the northern part of China, so the winter is warmer while the outdoor temperature is lower. Many college students are reluctant to participate in outdoor ice-snow sports. In response to this situation, college icesnow sports teaching should actively create an ice-snow sports atmosphere, and stimulate students' enthusiasm for ice-snow sports. Therefore, colleges and universities should adhere to the slogan of sunshine sports to reasonably arrange ice-snow sports courses, ice-snow sports exercise, and icesnow sports activities, etc., provide students with adequate ice and snow sports venues and sports guidance, meet the students' ice-snow sports needs, and train students' good icesnow sports habits, so that students can actively participate in ice-snow sports.

\section{Creating Ice-snow Sports Culture}

Sports culture has an important influence on the training of ice-snow sports talents in colleges and universities. Therefore, colleges and universities should actively create ice-snow sports culture and carry out special ice-snow sports teaching. To this end, colleges and universities should learn from the use of Russian ice-snow sports resources, implement the ice-snow sports strategy according to the geographical environment and development characteristics of the school, strengthen the ice-snow culture exchange with other schools, and draw on the excellent support of other schools' ice-snow culture to enhance the appeal of ice-snow culture to students. In addition, colleges and universities should create a characteristic ice-snow sports culture according to the teaching characteristics of the school, integrate the school's educational philosophy in the ice-snow sports teaching, and carry out the training of special ice-snow sports talents.

\section{Improving the Ice-snow Sports Course}

Ice-snow sports teaching in colleges and universities should actively draw on Heilongjiang ice-snow sports resources to improve ice-snow sports curriculum. For this reason, ice-snow sports teaching in colleges and universities should speed up the construction of ice-snow venues, improve the ice-snow sports teaching facilities, and actively open a variety of ice-snow sports courses such as skiing and ice hockey, deepen students' recognition of ice-snow sports, and let students fully understand the charm of ice-snow sports to promote the diversified development of school icesnow sports teaching. In addition, colleges and universities should actively open a variety of ice-snow sports activities such as ice-snow sports competitions and school ice-snow sports networking activities, to enrich students' ice-snow sports practice, and improve students' participation in icesnow sports.

\section{E. Increasing Publicity}

Colleges and universities should actively learn from the use of Russian ice-snow sports resources, and strengthen the 
publicity of ice-snow sports resources and ice and snow sports. Therefore, colleges and universities should actively promote the ice-snow sports culture, and promote the icesnow sports culture for students through campus radio, and school newspapers, etc., to enhance students' attention to the ice-snow sports culture, and stimulate students' interest in the ice-snow sports culture. Moreover, colleges and universities can also purchase books related to ice-snow sports culture and ice-snow sports to deepen students' understanding of icesnow sports. In addition, colleges and universities can also organize students to watch international ice-snow sports competitions, let students understand the charm of ice-snow sports, stimulate students' interest in ice-snow sports, and promote the training of ice-snow sports talents.

\section{CONCLUSION}

In summary, as far as the current situation of ice-snow sports talents training in colleges and universities is concerned, there are still many problems in carrying out icesnow sports teaching and talent training such as limited funds, difficulty in paying high venue funding, transportation funds and academic aid funds, lack of teaching innovation consciousness, monotonous content of ice-snow sports teaching, difficulty in forming characteristic ice-snow physical education curriculum; single curriculum model; incomplete professional faculty and team. In order to highlight the development of ice-snow sports education and strengthen the training of China's ice-snow sports reserve talents, it still needs school and enterprise to carry out multiparty cooperation, jointly advocate and active use superior resources to promote the development of China's ice-snow sports talents to a higher level and specialized direction together.

\section{REFERENCES}

[1] Zhang Hongbo, Lian Yang. Construction of urban ice-snow sports culture system with regional characteristics [J]. Sports Science and Technology, 2014(02).

[2] Ai Shuhua, Peng Jie. Exploration of the development status of the ice-snow sports culture industry chain in Heilongjiang Province [J]. Industrial \& Science Tribune, 2016(02)

[3] Cheng Xianxu. Development status and countermeasures of ice-snow sports industry in Heilongjiang province[J]. Contemporary Sports Technology, 2017(32).

[4] Shi Jing. Research on the development strategy of ice-snow sports culture industry in Heilongiiang Province [J]. sports world Scholarly, 2017(06).

[5] Li Changzhu. On the role of ice-snow culture resources of China and Russia in ice-snow sports culture of college and universities in Heilongjiang Province [J]. Contemporary Sports Technology, 2017(02).

[6] Li Changzhu. Research on sports exchange between universities in Heihe border under the background of Sino-Russian cooperation [J]. Brand, 2014(12).

[7] Li Changzhu. Innovative research on the ice-snow sports industry in Heilongjiang Province [J]. Journal of Jiamusi Vocational Institue. 2018(04). 